\title{
Rare case of ruptured uterus in previously normal delivered patient due to hydatid cystic disease in pregnant uterus
}

\section{Ganesh Mahadeo Bargaje, Jitendra Pundlik Ghumare*}

Department of Obstetrics and Gynecology, SBH Govt. Medical College, Dhule, Maharashtra, India

Received: 22 May 2019

Accepted: 09 July 2019

\section{* Correspondence:}

Dr. Jitendra Pundlik Ghumare,

E-mail: researchexpert3@gmail.com

Copyright: () the author(s), publisher and licensee Medip Academy. This is an open-access article distributed under the terms of the Creative Commons Attribution Non-Commercial License, which permits unrestricted non-commercial use, distribution, and reproduction in any medium, provided the original work is properly cited.

\begin{abstract}
Hydatid cystic disease is parasitic disease caused by Echinococcus granulosus. Dogs and carnivors like fox are definitive hosts harbouring warms in intestine. Eggs passed in stools eaten by intermediate hosts and larvae encyst in liver, lungs and other organs. Humans are accidental hosts. Incidence of hydatid cystic disease in genital organs is low around $0.5 \%$. Hydatid cyst most often found in liver - 60\%, lungs - 30\% accounting approximately $90 \%$ of the disease. Incidence of hydatid disease in pregnancy is very rare ranging from 1/20000 to 1/30000. 22 years old G2P1L1 with 39weeks gestation age (GA) with intrauterine fetal death (IUFD) with query ruptured uterus, extra uterine pregnancy, transverse lie with severe anaemia referred from Jalgaon civil hospital for further management.
\end{abstract}

Keywords: Hydatid cystic disease, Pregnancy, Echinococcus granulosus, Intrauterine fetal death

\section{INTRODUCTION}

Hydatid cystic disease is parasitic disease caused by Echinococcus granulosus. Dogs and carnivors like fox are definitive hosts harbouring warms in intestine.

Echinococcosis or hydatid disease is an infection of sheep, cattle, pigs, horses or rodents caused by larval stage of canine tapeworm Echinococcus granulosus or Echinococcus multilocularis. Hydatid cysts due to the former are found more commonly in sheep-rearing areas of the world namely Australia, New Zealand, Argentina, Chile, India and Mediterranean region. ${ }^{1}$ Parasites are found in dogs (definitive hosts) and in sheep (intermediate hosts). The adult worm is located at the intestine of dogs; eggs or oncospheres are passed in the dog's stool. ${ }^{2}$ Humans get infected by ingesting eggs, as people are intermediate hosts in the life cycle of worms. ${ }^{3}$ This occurs when people consume food or drinks contaminated with eggs or come into contact with fecal material containing eggs. ${ }^{4}$

Incidence of hydatid cystic disease in genital organs is low around $0.5 \%$. Hydatid cyst most often found in liver $60 \%$, lungs $-30 \%$ accounting approximately $90 \%$ of the disease. Incidence of hydatid disease in pregnancy is very rare ranging from $1 / 20000$ to $1 / 30000$.

Hydatid cysts during pregnancy are rare and there is no standardized recommended treatment. Both surgical and medical modalities have been tried. Hydatid disease of the liver is common in India; though it has not been reported during pregnancy from this part of India.

\section{CASE REPORT}

22years old G2P1L1 with 39weeks gestation age (GA) with Intrauterine fetal death (IUFD) with query ruptured 
uterus, extra uterine pregnancy, transverse lie with severe anaemia referred from Jalgaon civil hospital for further management.

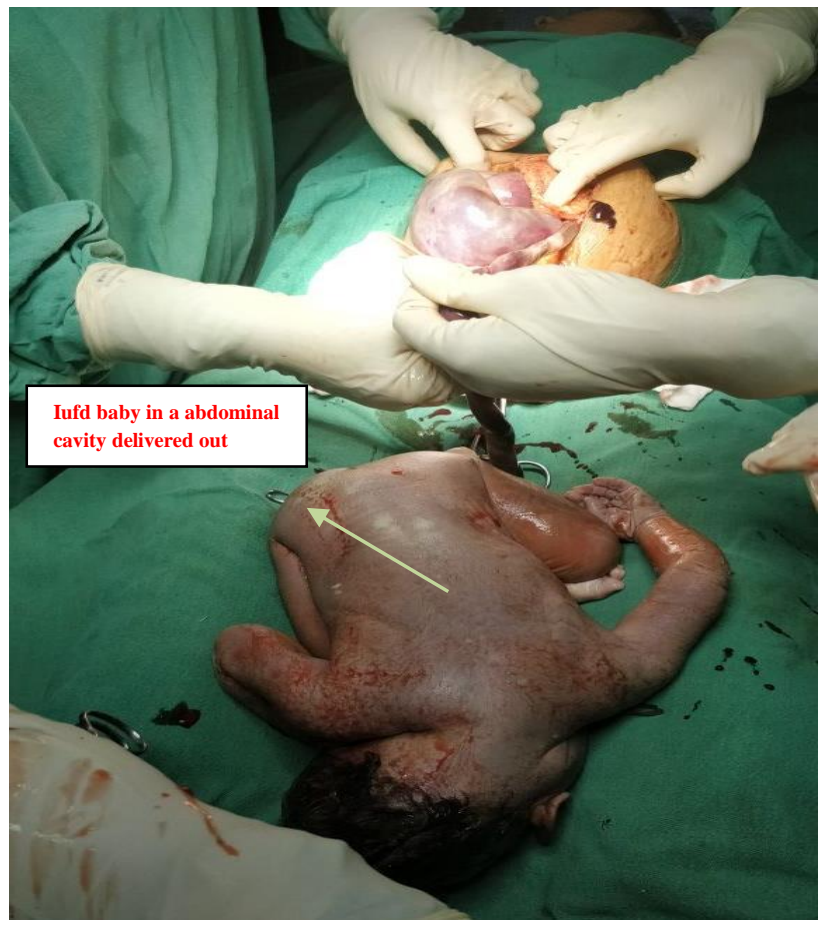

Figure 1: IUFD delivery.

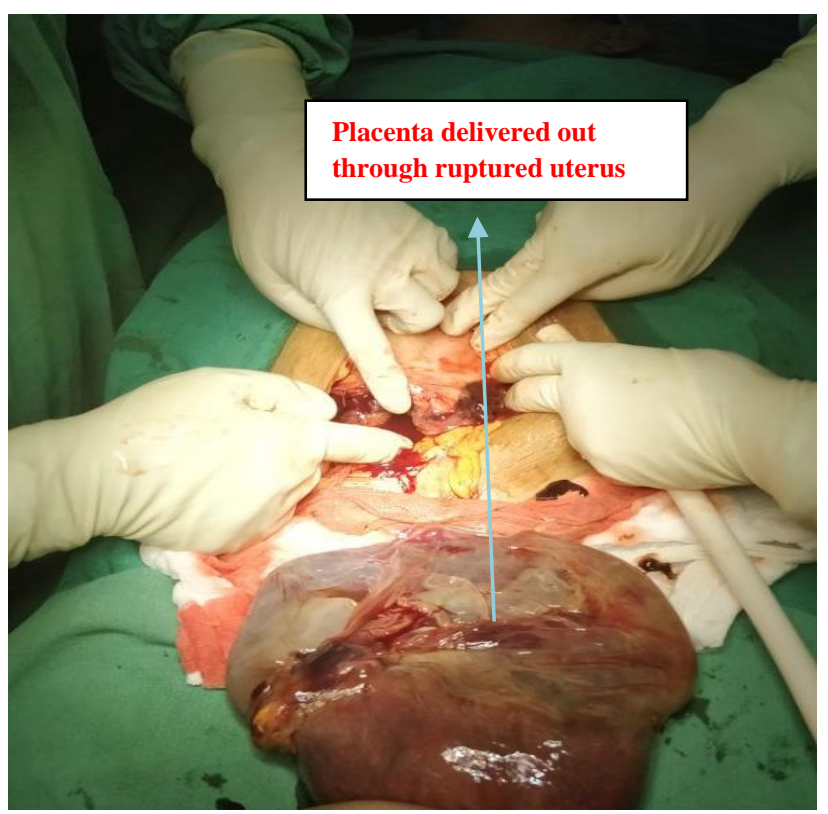

Figure 2: Placenta delivered.

Patient has given history of chief complaints of pain in abdomen, fatigue, weakness since 2 days patient has started labour pain since 2 days with increasing frequency and intensity of contraction for about one day and suddenly loss of contraction and pain with increasing complaints of weakness and fatigue. On general examination patient having tachycardia with normal hypertension, severe pallor. Patient haemoglobin was $5.8 \mathrm{gm}$ and received one bag of blood during transfer. On per abdominal examination there was distension with multiple fetal parts palpable with presence of guarding, rigidity and tenderness. Fetal heart sound was not appreciable. Per vaginal examination os was closed with no bleeding, leaking or any discharge.

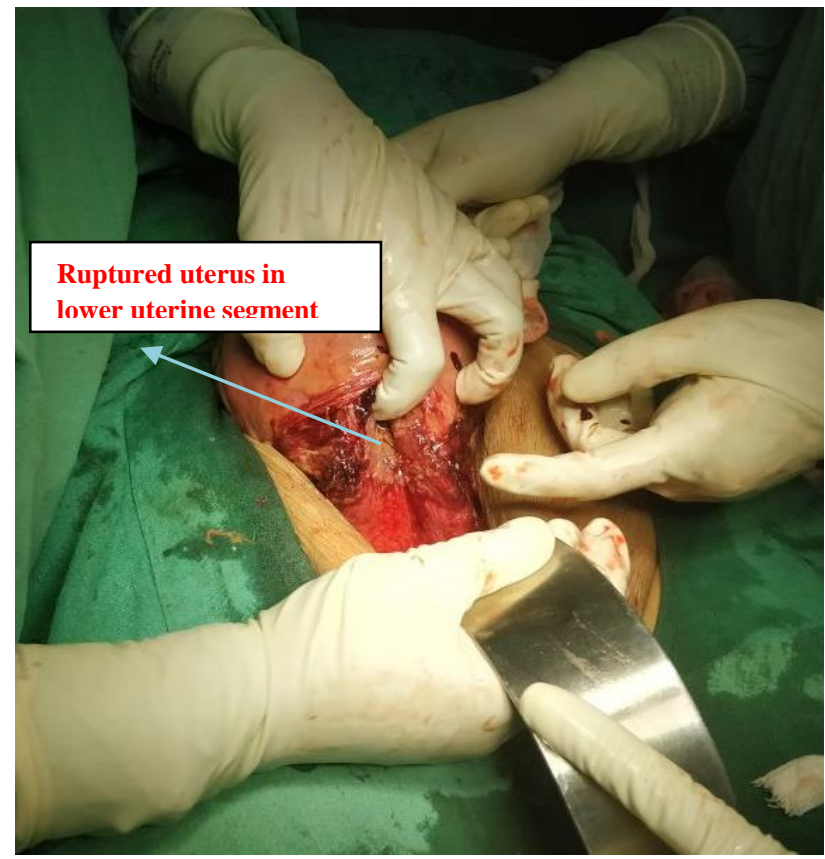

Figure 3: Ruptured uterus in LUS.

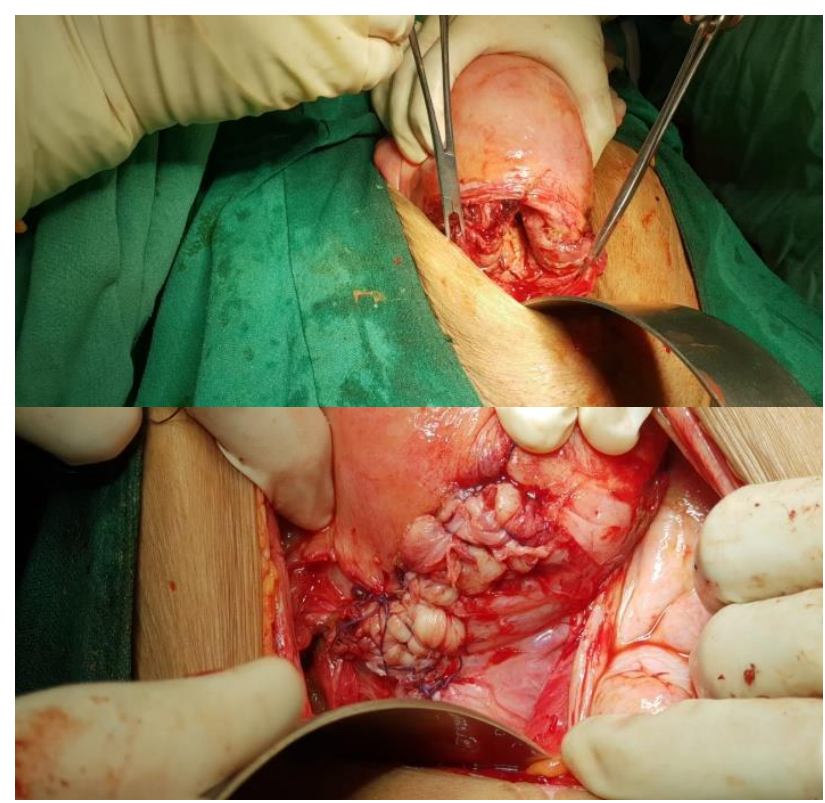

Figure 4: Large vertical rent in lower uterine segment sutured with vicryl.

Her obstetric history was 3 years old living male child Full term normal delivery (FTND). She was unregistered and belongs to shepherd community. She has only recent ultrasound of 2-3 days back suggestive of single live 
intrauterine pregnancy of 36.5 weeeks GA with cephalic presentation. Referral day ultrasound shows IUFD with query extrauterine pregnancy, ruptured uterus. Ultrasound done at our hospital single fetus of 35 weeks GA, absent FHS in abdominal cavity with positive spalding sign. Gross hemoperitoneum with dilated and aperistaltic bowel loops noted. $14 \times 14 \mathrm{~cm}$ left adnexal cyst with multiple septation noted. Radiologist gives opinion of parovarion cyst or myoma.

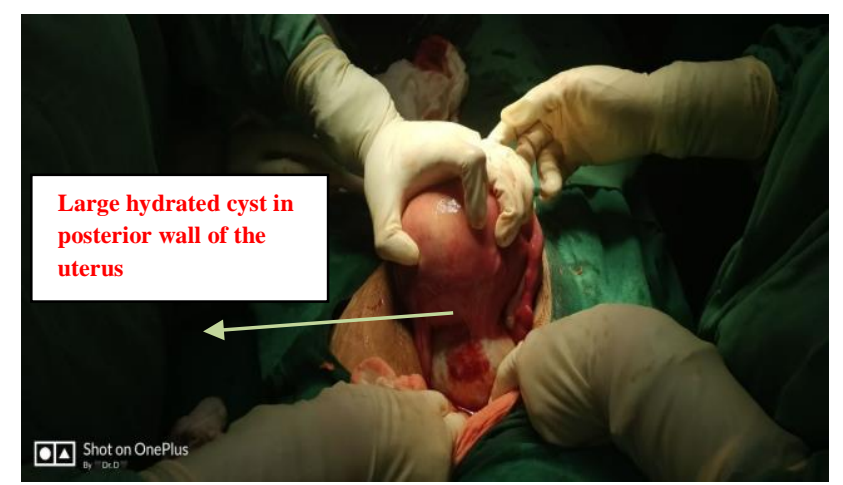

Figure 5: Large hydatid cyst in posterior wall of the uterus.

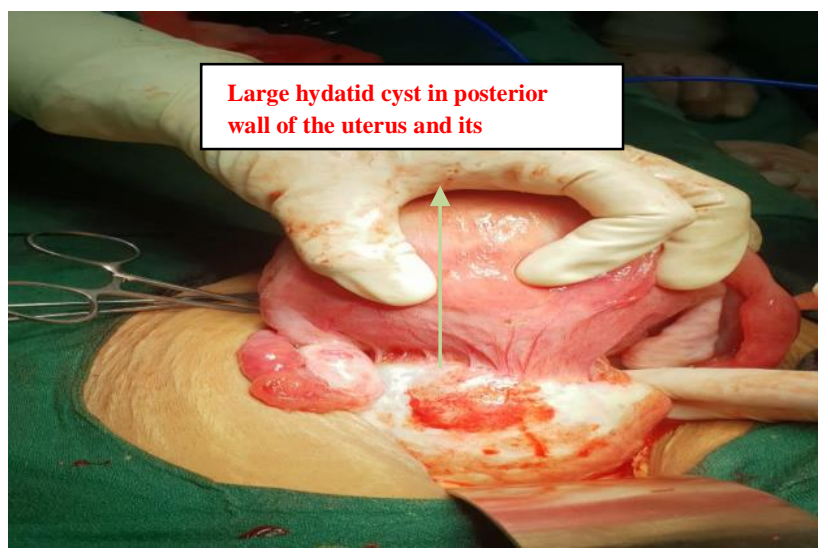

Figure 6: Large hydatid cyst in posterior wall of the uterus and its attachment.

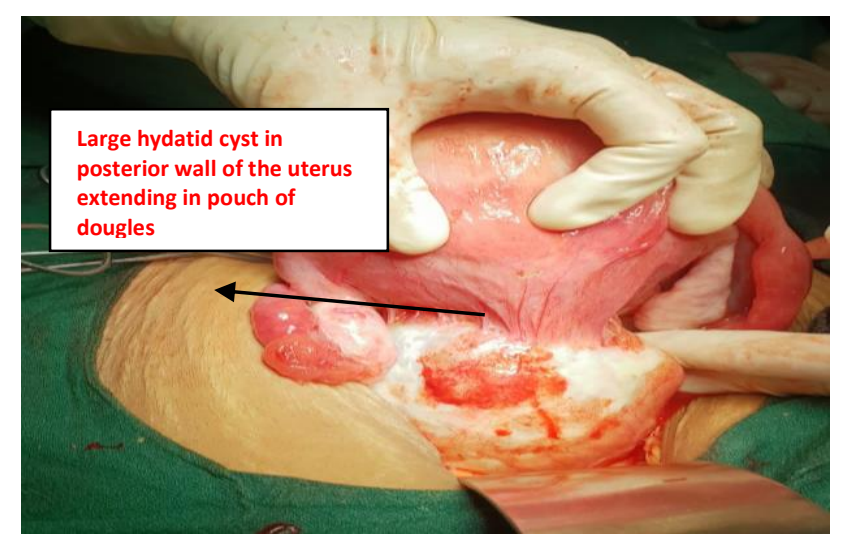

Figure 7: Large hydatid cyst in posterior wall of the uterus extending in pouch of dougles.

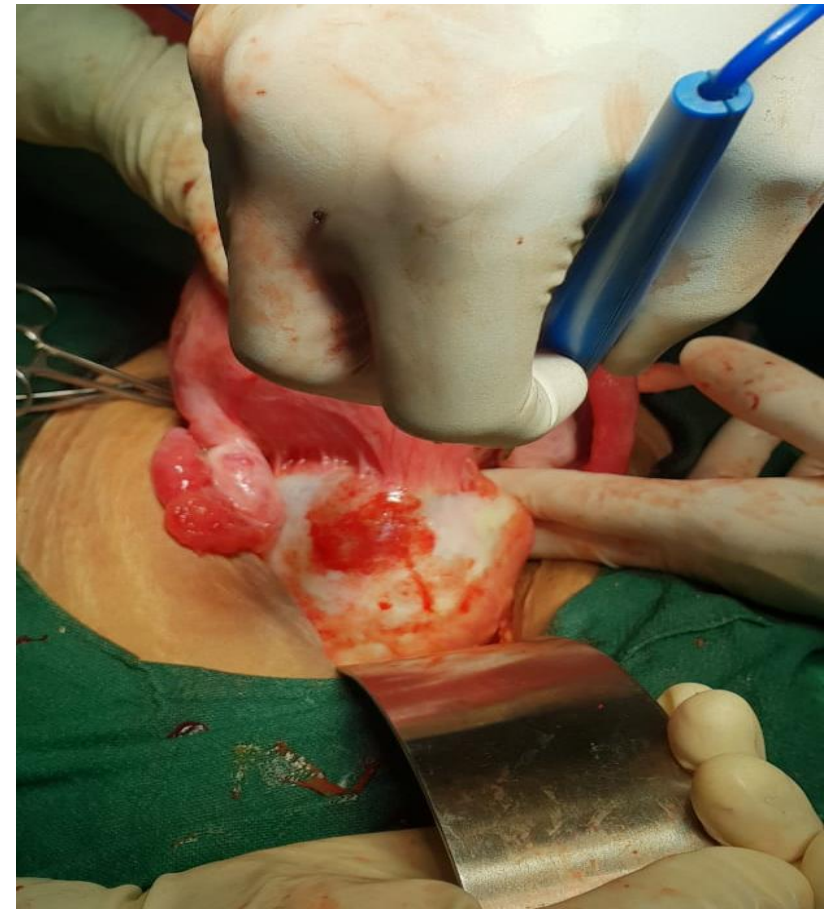

Figure 8: Excision of hydatid cyst with the help of cautary.

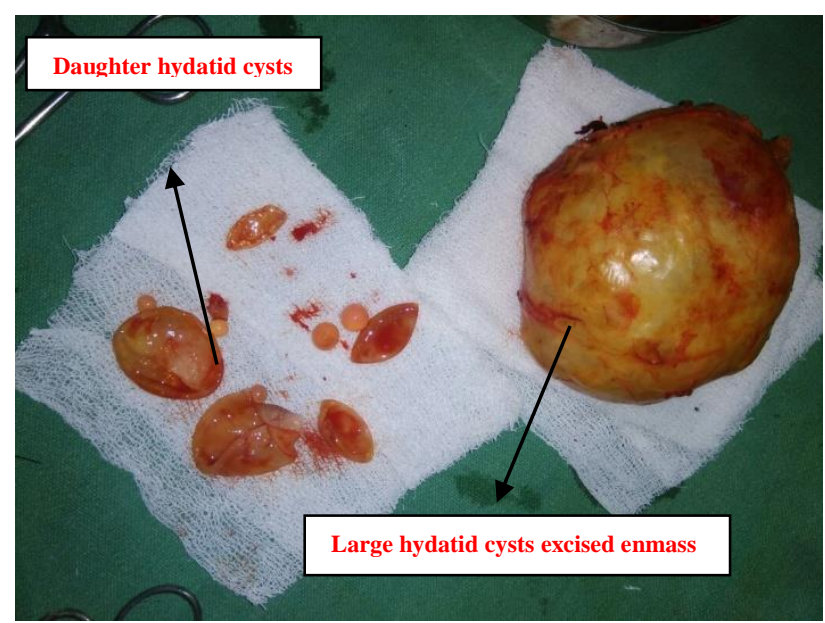

Figure 9: Large and daughter hydatid cysts.

Arrangement of blood, FFP preoperative prepation done patient shifted to operation theatre. Abdomen was opened $2.6 \mathrm{~kg}$ IUD (intrauterine death) female child in macerated condition. Placenta delivered out (Figure 1 and 2). Approximately $100 \mathrm{cc}$ of hemoperitoneum was present. Suction irrigation done. Uterus in lower uterine segment was ruptured with having 7-8 cm vertical rent with irregular border (Figure 3). Edges were freshened and suturing done with vicryl no. 1-0. Anteriorly hemostasis achieved (Figure 4).

In posterior wall of uterus approximately $10 \times 10 \mathrm{~cm}$ cystic structure was noted in pouch of Douglous. (Figure 5, 6, and 7) Initially it was looking like degenerated myoma. It was the reason for obstructed labour leading to ruptured 
uterus. Surgeon was called due to suspicion of hydatid cyst and decision of excision of cyst was taken (Figure 8). Small adhesions of bowel and uterus released and Cyst excised en-masse. Cyst specimen taken on different trolly and punctured multiple daughter cysts emerged from within big cyst (Figure 9). Clinically it was hydatid cyst later on histopathology report also confirms the diagnosis. Whole abdominal cavity was explored for another cyst. No other cyst was found. Hemostasis was checked. Bilateral peristaltic movements of ureters checked. Intraoperative field was irrigated with scolicidal 10 percent polyvinylpyrrolidone-iodine solution. Abdomen closed in layers. Postoperative period was not eventful. IV Cefosalbactum, metronidazole analgesics and tab albendazole for 1 month was given. Anaemia was corrected with blood and FFP transfusion. Sutures removed on 8th post operative day. Histopathology reports were consistent with hydatid cyst. Patient advised tab albendazole for 1month and follow uop after for further management. Patient discharged on 8 th post op day.

\section{DISCUSSION}

Hydatid disease in pregnancy only few cases in pelvic region have been documented till now. Symptoms are often absent and many times detected accidently by imaging study. Complications occurring during pregnancy are abdominal pain, dystocia, obstructed labour, uterine rupture, torsion, anaphylactic shock occurring during rupture of cyst. Our patient was presented with ruptured uterus as patient was unregistered and not diagnosed antenatally. In our case USG reports suggestive of paraovarian cyst or myoma. Serological markers are less reliable in pregnancy. ${ }^{5}$

The management of hydatid disease in pregnancy has issue of safety of drugs during pregnancy; timing of surgery is difficult to decide. Drugs like albendazole and mebendazole are teratogenic for animals and safety of drugs in first trimester is not proved yet though we can give it in second and third trimester if necessary.

Primary involvement of pelvic organ is very rare. Our case presented as hydatid cyst in posterior uterine wall causing obstruction of labour which leads to uterine rupture. No other cysts were present in abdominal cavity thus can be considered as primary involvement. Infection to pelvic region can be by hematogenous or lymphatic route. Patient was also belongs to shepherd community.

Medical treatment consists of oral albendazole. Response to Albendazole depends on thickness of the cyst wall and the absence of calcifications. However, it cannot be used in the first trimester due to the risk of teratogenicity.
Commonly reported anomalies if given in first trimester include limb defects and facial abnormalities. ${ }^{6}$ One case of liver hydatosis during pregnancy diagnosed at 25 weeks of gestation which was successfully managed by medical treatment only with oral albendazole was report earlier from India. ${ }^{6}$ Vliet $\mathrm{V}$ et al managed a 20 -year-old Turkish woman with three huge echinococcus cysts of the liver who was admitted in the third trimester of pregnancy. During pregnancy she received albendazole and during vaginal delivery she received both albendazole and medication aimed at preventing anaphylactic reaction (corticosteroids). ${ }^{6}$

Surgery may be conservative or extensive. Surgery is still the first choice for type III cysts, type IV cysts, and cysts opening into the bile ducts or peritoneal cavity. There is often no need for therapy for type $\mathrm{V}$ hydatid cysts.

\section{CONCLUSION}

In conclusion gynaecologists should be kept in mind one of differential diagnosis of pelvic or adnexal mass in pregnancy may be hydatid disease though it is very rare.

\section{Funding: No funding sources \\ Conflict of interest: None declared \\ Ethical approval: Not required}

\section{REFERENCES}

1. Nutman TB, Weller PF, Cestodes. In: Kasper DL, Braunwald E, Hauser S, Longo D, Jameson JL, Fauci AS, editors. Harrison's Principles of Internal Medicine. $16^{\text {th }}$ ed. Mc-graw Hill; New York: 2004:1225-6.

2. Hydatid cysts in a pregnant uterus Dr Pravin Kumar Thakare GMC Yawatmal. J Obstet Gynaecol India. 2014;64(3):215-7.

3. Bagul A, Kavak ZN, Gokaslan H. Hydatid cyst of uterus. Infect Dis Obstet Gynaecol. 2002;10:67-70.

4. Sachin E, Nayki U, Sadik S. Abdominal and pelvic hydatid disease during pregnancy. Arch Gynaecol Obstet. 2005;273:58-9.

5. Malhotra N, Chanana C, Kumar S. Hydatid disease of the liver during pregnancy: a case report and review of literature. Int J Gynecol Obstet. 2007;7.

6. Van Vliet W, Scheele F, Sibinga-Mulder, Dekker GA. Echinococcosis of the liver during pregnancy. Int J Gynecol Obstet. 1995;49:323-4.

Cite this article as: Bargaje GM, Ghumare GP. Rare case of ruptured uterus in previously normal delivered patient due to hydatid cystic disease in pregnant uterus. Int J Reprod Contracept Obstet Gynecol. 2019;8:3398-401. 